\title{
Effect of Chitosan Dissolved in Different Acids on Its Ability to Control Postharvest Gray Mold of Table Grape
}

\author{
Gianfranco Romanazzi, Franka Mlikota Gabler, Dennis Margosan, Bruce E. Mackey, and Joseph L. Smilanick
}

First author: Department of Environmental and Crop Science, Marche Polytechnic University, via Brecce Bianche, 60131 Ancona, Italy; second author: Institute for Adriatic Crops, Put Duilova 11, 21000 Split, Croatia; third and fifth authors: United States Department of Agriculture-Agricultural Research Service (USDA-ARS), San Joaquin Valley Agricultural Sciences Center, 9611 South Riverbend Ave. Parlier, CA 93648; and fourth author: Biometrical Services, USDA-ARS, Western Regional Research Center, 800 Buchanan Street, Albany, CA 94710-1105.

Accepted for publication 22 April 2009.

\begin{abstract}
Romanazzi, G., Mlikota Gabler, F., Margosan, D., Mackey, B. E., and Smilanick, J. L. 2009. Effect of chitosan dissolved in different acids on its ability to control postharvest gray mold of table grape. Phytopathology 99:1028-1036.

Chitosan is a natural biopolymer that must be dissolved in an acid solution to activate its antimicrobial and eliciting properties. Among 15 acids tested, chitosan dissolved in $1 \%$ solutions of acetic, L-ascorbic, formic, L-glutamic, hydrochloric, lactic, maleic, malic, phosphorous, and succinic acid. To control gray mold, table grape berries were immersed for $10 \mathrm{~s}$ in these chitosan solutions that had been adjusted to $\mathrm{pH}$ 5.6. The reduction in decay among single berries of several cultivars (Thompson

chitosan acetate or formate, followed by storage at $15^{\circ} \mathrm{C}$ for 10 days, was $\approx 70 \%$. The acids alone at pH 5.6 did not control gray mold. Decay among clusters of two cultivars (Thompson Seedless and Crimson Seedless) inoculated before treatment was reduced $\approx 60 \%$ after immersion in chitosan lactate or chitosan acetate followed by storage for 60 days at $0.5^{\circ} \mathrm{C}$. The viscosity of solutions was 1.9 centipoises (cp) (ascorbate) to $306.4 \mathrm{cp}$ (maleicate) and the thickness of chitosan coating on berries was $4.4 \mu \mathrm{m}$ (acetate) to $15.4 \mu \mathrm{m}$ (ascorbate), neither of which was correlated with solution effectiveness. Chitosan acetate was the most effective treatment which effectively reduced gray mold at cold and ambient storage temperatures, decreased $\mathrm{CO}_{2}$ and $\mathrm{O}_{2}$ exchange, and did not injure the grape berries.
\end{abstract} Seedless, Autumn Seedless, and grape selection B36-55) inoculated with Botrytis cinerea at $1 \times 10^{5}$ conidia/ml before or after immersion in

Chitosan, an $\mathrm{N}$-acetylated derivative of the polysaccharide chitin, is a biopolymer which has been the object of considerable interest for applications in agriculture, biomedicine, biotechnology, and the food industry due to its biocompatibility, biodegradability, and bioactivity (43). Research to reduce fungicide applications by the discovery of new natural antimicrobials is needed to meet a growing consumer demand for food without chemical preservatives $(16,19)$. Chitosan was reported to prolong storage life and control decay of several fruit (6). In previous works, preharvest chitosan applications on grape effectively controlled gray mold arising from natural infections that occurred in the vineyard $(35,37)$. The biopolymer has a dual mechanism: it inhibits the growth of decay-causing fungi (14) and induces defense response in the host (2). Several commercial chitosan formulations are available on the market, such as Elexa-4 and Chitogel (16), and Chito Plant (ChiPro, Bremen, Germany) was recently added to the list (38). However, the most common form of chitosan from crab shells needs to be dissolved in slightly acidic solutions. Several organic and inorganic acids are reported to effectively dissolve chitosan, including acetic (1), formic (7), L-glutamic (33), lactic (7), hydrochloric (15), and malic (12) acids, in studies where antimicrobial activity or physical properties

Corresponding author: G. Romanazzi; E-mail address: g.romanazzi@univpm.it

* The $\boldsymbol{e}$-Xtra logo stands for "electronic extra" and indicates that the online version contains three supplemental tables showing the effectiveness of chitosan dissolved in different acids to control gray mold and regression equation parameter estimates to predict carbon dioxide and oxygen content in bags containing grape clusters treated with chitosan.

doi:10.1094/PHYTO-99-9-1028

(C) 2009 The American Phytopathological Society
Additional keywords: carbon dioxide, oxygen, Vitis vinifera. are determined. However, no comparison of activity of chitosan dissolved in different acids to control plant diseases has been done.

Gray mold, caused by Botrytis cinerea Pers., is responsible for significant losses of table grape berries both in the field and after harvest, where it is a major obstacle to their long-distance transport and storage. It is the most economically important postharvest disease of this commodity (11). Control of gray mold is especially important in cold storage because it develops at cold temperatures $\left(-0.5^{\circ} \mathrm{C}\right)$ and spreads rapidly among berries. Currently, gray mold is controlled before harvest by canopy management in combination with fungicide applications, and after harvest by sulfur dioxide fumigation $(11,16,19)$. However, alternatives are needed because sulfur dioxide can cause bleaching of the berries and browning of the rachis (27), and its residues could be harmful for people allergic to sulfites. Concerns about sulfite residues in grape berries and other foods caused sulfur dioxide to be removed in 1986 from the United States Food and Drug Administration Generally Recognized as Safe (GRAS) compound list (3).

When dissolved in acetic acid, chitosan is effective in reducing gray and blue molds of table grape $(9,35,37,44)$. The treatment with the biopolymer induced phenylalanine ammonia-lyase (PAL) activity $(23,37)$ in treated berries and primed the production of trans-resveratrol and catechin (35). Moreover, chitosan treatment triggered the accumulation of trans- and cis-resveratrol and their derivatives $\varepsilon$-viniferin and piceid in grapevine leaves (4). It is not known whether treatment of grape berries with chitosan dissolved in acids other than acetic can be effective in controlling gray mold, and no information is available on the properties of chitosan coating or its effect on gas exchange of stored grape berries, or whether the treatment with the biopolymer can stimulate hydrogen peroxide production in the berry skin, which is one of the first steps of induction of resistance in the host (28). 
The objectives of this study were to (i) investigate the ability of various acids to dissolve chitosan, (ii) determine whether acids used to dissolve the biopolymer would influence its effectiveness to control postharvest decay of table grape, (iii) quantify the coating properties of chitosan films on the berries, (iv) evaluate the effect of the coating on carbon dioxide and oxygen exchange of stored grape berries, and (v) assess the ability of chitosan to induce hydrogen peroxide in berry skin.

\section{MATERIALS AND METHODS}

Table grape. Table grape (Vitis vinifera L.) cvs. Thompson Seedless, Autumn Seedless, Crimson Seedless, and selection B3655 (a cross between $V$. vinifera, $V$. rupestris Scheele, and $V$. lincecumii Buchkl.) were harvested from a United States Department of Agriculture-Agricultural Research Service (USDAARS) vineyard in Fresno, CA. Table grape cv. Italia was harvested from a vineyard in Marche Region, central-eastern Italy. No fungicides were applied prior to harvest. Table grape cv. Perlette, used in preliminary trials, was obtained from a local store in Parlier, CA. Mature clusters from several grapevines were harvested. Before the treatments, the soluble solids content of the berries was determined by an hand held Brix refractometer (RHB32 ATC; Westover Scientific, Mill Creek, WA) using a sample of randomly selected berries. Only clusters with soluble solids content of $\geq 16 \%$ were included in the tests. Trials were carried out on both single berries and small clusters of $\approx 100$ g each containing $\approx 25$ berries.

Acids. Fifteen acids were selected to assess their ability to dissolve chitosan (Sigma-Aldrich, St. Louis). All acids were used at $1 \%$ of active ingredient ( $\mathrm{vol} / \mathrm{vol}$ for liquid or $\mathrm{wt} / \mathrm{vol}$ for powder formulations) (Table 1). All reagents were purchased from SigmaAldrich, except formic acid (Fisher Scientific, Pittsburg).

Chitosan. Crab-shell chitosan was ground to a fine powder in a mortar, washed three times with distilled water, pelleted by lowspeed centrifugation, and air dried at $20 \pm 2{ }^{\circ} \mathrm{C}$. The purified chitosan was prepared as described by Benhamou et al. (8). For experimental use, the solution $(1 \%, \mathrm{wt} / \mathrm{vol})$ of chitosan was prepared by dissolving, under continuous stirring, the purified chitosan in $1 \%$ solution of the acids (Table 1). When necessary, acid solutions were heated at $60^{\circ} \mathrm{C}$ to improve the solubility of chitosan. When dissolved, the $\mathrm{pH}$ of the solutions was adjusted to 5.6 using $1 \mathrm{~N} \mathrm{NaOH}$, followed by the addition of $0.1 \%$ (wt/vol) of surfactant Triton X-100 to improve their adhesion properties.

Inoculum preparation. $B$. cinerea isolate 1440 from grape (a gift from Themis Michailides, Kearney Agricultural Center, Parlier, CA) was stored at $-80^{\circ} \mathrm{C}$ on silica gel and grown on potato dextrose agar (PDA) for 2 weeks at $20 \pm 2^{\circ} \mathrm{C}$ when needed. Spores were gently rubbed from the agar surface with a glass rod after a small volume of sterile water containing Triton X-100 at $0.05 \%$ (wt/vol) was added to the plate. The spore suspension was vigorously shaken and filtered through four layers of cheesecloth. The suspension was diluted with sterile water to an absorbance of 0.25 at $425 \mathrm{~nm}$ as determined by a spectrophotometer. This density contained $\approx 1.0 \times 10^{6}$ conidia/ml and was diluted with sterile water to obtain the desired spore concentrations. A volume of $100 \mathrm{ml}$ of inoculum was applied with an air-brush sprayer to $\approx 1,200$ berries or 150 small clusters.

Treatment of single detached berries. Healthy single berries, with the pedicel intact, were cut from the rachis, pooled together, and randomized. In the first set of experiments, berries were inoculated by spraying them with a suspension of $1.0 \times 10^{5}$ conidia/ml and drying in air for $30 \mathrm{~min}$, then immersing them for $10 \mathrm{~s}$ in a volume of 1 liter of the chitosan solutions. The experiment was repeated three times, once each on cvs. Thompson Seedless, Autumn Seedless, and the selection B36-55. A second set of experiments were conducted with grape cv. Italia to evalu- ate the effectiveness of each of the acids alone on the incidence of gray mold infections. In this test, a $1 \%$ solution of each acid (Table 1) was adjusted to $\mathrm{pH} 5.6$, as were the chitosan solutions, and berries previously inoculated with the pathogen were immersed in the acid solutions. At the same time, Italia berries that had been inoculated as described previously were treated with the chitosan solutions. The experiment was repeated twice. In all trials, berries immersed in deionized water at $\mathrm{pH} 5.6$ were used as a control. In another set of experiments, single berries of the selection B36-55 were first immersed for $10 \mathrm{~s}$ in the chitosan solution and, $30 \mathrm{~min}$ later, spray inoculated with $B$. cinerea. Berries immersed in deionized water at $\mathrm{pH} 5.6$ were used as controls. The experiment was repeated twice with berries of the selection B36-55. After treatment, the berries were dried in air for $30 \mathrm{~min}$, individually arranged on wire racks to avoid contact among them, placed in covered plastic boxes lined with moist paper towels, and stored at $15 \pm 1{ }^{\circ} \mathrm{C}$ and 95 to $98 \%$ relative humidity $(\mathrm{RH})$ for 7 days. Three replicates of 50 single berries each were used for each treatment.

Treatment of table grape clusters. Grape clusters were cut into small clusters of $\approx 100 \mathrm{~g}$ each and randomized so that a portion of each cluster was represented in each treatment. Grape clusters were inoculated by briefly spraying them with a suspension of $1.0 \times 10^{5}$ conidia $/ \mathrm{ml} 30 \mathrm{~min}$ prior to treatment; then, the clusters were immersed for $10 \mathrm{~s}$ in chitosan solutions and air dried on a wire rack. The clusters were placed in ventilated polyethylene cluster bags (VPE) (bag size, 236 by $280 \mathrm{~mm}^{2}$; thickness, $0.05 \mathrm{~mm}$; 124 perforations, $6 \mathrm{~mm}$ in diameter; vented area, $2.7 \%$ ) and arranged in commercial corrugated fiberboard boxes. Clusters treated with deionized water at $\mathrm{pH} 5.6$ were used as controls. Each replicate consisted of one bag with $\approx 500 \mathrm{~g}$ of grape berries and each treatment was applied to five replicates. Boxes were loosely covered with large polyethylene bags to retard moisture loss and placed in storage at $0.5 \pm 1^{\circ} \mathrm{C}$ for 60 days, followed by 3 days at $25 \pm 1^{\circ} \mathrm{C}$ to simulate commercial marketing conditions. The experiment was done twice, once each with grape cv. Thompson Seedless and cv. Crimson Seedless.

Decay assessment. Gray mold incidence was recorded as the number of decayed berries. In the experiments with single berries, disease severity was assessed according to the following empirical scale: $0=$ healthy berry; $1=$ one lesion, 2 to $3 \mathrm{~mm}$ in diameter (beginning of infection); 2 = one lesion, $10 \mathrm{~mm}$ in diameter; $3=$ several lesions or $25 \%$ of the berry infected; $4=26$ to $50 \%$ of the berry surface infected, sporulation present; $5=>50 \%$ of the berry surface infected, sporulation present (35). Blue mold infections arising from natural Penicillium spp. inoculum present on grape berries were also recorded.

TABLE 1. Acids used to dissolve purified chitosan for use in postharvest trials

\begin{tabular}{lcc}
\hline Acid & pH of $1 \%$ solution & $\begin{array}{c}\text { Ability to dissolve the } \\
\text { biopolymer }^{\mathrm{a}}\end{array}$ \\
\hline Acetic & 2.8 & Yes \\
L-ascorbic & 2.7 & Yes $^{\mathrm{b}}$ \\
Boric & 5.0 & No \\
DL- $\alpha$-aminobutyric & 5.4 & No \\
Formic & 2.2 & Yes \\
Gallic & 2.9 & No \\
L-glutamic & 2.6 & Yes $^{\mathrm{b}}$ \\
Hydrochloric & 0.6 & Yes $^{\mathrm{b}}$ \\
Lactic & 2.4 & Yes \\
Maleic & 1.5 & Yes \\
Malic & 2.3 & Yes \\
Phosphorous & 1.4 & Yes \\
Polygalacturonic & 3.0 & No \\
Succinic & 2.6 & Yes \\
Trans-cinnamic & 2.9 & No
\end{tabular}

${ }^{a}$ Evaluation of chitosan dissolution was based on visual assessment of the solution.

${ }^{\mathrm{b}}$ Acid needed to be warmed to dissolve the chitosan. 
Cold storage gas exchange study. Grape clusters immersed in chitosan solutions or deionized water at $\mathrm{pH} 5.6$ as previously described were air dried on a wire rack and enclosed in 0.5-liter, 0.03-mm-thick Ziploc sandwich plastic bags (S. C. Johnson and Son Inc., Racine, WI). Each replicate consisted of one bag of $\approx 500 \mathrm{~g}$ grape berries and each treatment was applied to five replicates. Grape berries were stored at $0.5 \pm 1{ }^{\circ} \mathrm{C}$ for 60 days as described previously. The oxygen $\left(\mathrm{O}_{2}\right)$ and carbon dioxide $\left(\mathrm{CO}_{2}\right)$ contents were recorded weekly during a 5-week period by withdrawing a 10-ml gas sample with a syringe from the bags of grape berries and injecting it immediately into a portable electrochemical gas analyzer (MAPtest 4050; Hitech Instruments, Luton, England) (34). Trials were repeated twice, once each on grape cv. Thompson Seedless and cv. Crimson Seedless.

Viscosity. The viscosity of the chitosan solutions was assessed by the falling ball method (21). A viscometer GV-2100 (Gilmont Instruments, Barrington, IL, USA) was used for the solutions with viscosity $<20$ centipoises (cp) and a model viscometer GV-3100 was used for the solutions with viscosity $>20 \mathrm{cp}$. The viscosity $(\mu)$ was calculated using the formula $\mu=K\left(p_{f}-p\right) t$, where $K$ is a viscometer constant, $p_{f}$ the density of the ball $(\mathrm{g} / \mathrm{ml}), p$ the density of the liquid $(\mathrm{g} / \mathrm{ml})$, and $t$ the time of descent (min). Each assessment was repeated three times and each value was the mean of five readings. Relative viscosity was calculated by considering the water viscosity.

Chitosan coating characterization. Two berries of cv. Crimson Seedless immersed in chitosan solutions for $10 \mathrm{~s}$ and air dried for $1 \mathrm{~h}$ were selected and a small circle around the midpoint of each berry was made with a marking pen. A $20 \mu \mathrm{g} / \mathrm{ml}$ solution $(30 \mu \mathrm{l})$ of Alexa Fluor 488-wheat germ agglutinin conjugate (Molecular Probes, Inc., Corvallis, OR) in phosphate-buffered saline (PBS) was placed in the center of the mark. The berries were incubated in a moist chamber for $20 \mathrm{~min}$, before the stain solution was washed off with fresh PBS. A section of the berry ( 0.5 to $1 \mathrm{~mm}$ thick) was cut using a razor blade and was mounted on a microscope slide, and $\mathrm{z}$ series were collected through the thickness of the chitosan coating with a confocal laser scanning microscope (Leica 4D TCS; Leica, Deerfield, IL) with an excitation of $488 \lambda$. The $\mathrm{z}$ series were reconstructed with VoxBlast (VeyTek, Inc., Fairfield, IA) and the thickness of the chitosan coating measured at five points with NIH Image software (National Institute of Health, Bethesda, MD). The experiment was repeated twice.

Detection of reactive oxygen species. Reactive oxygen species (ROS) induction was evaluated in berry skin tissues of the selection B36-55 based on hydrogen peroxide $\left(\mathrm{H}_{2} \mathrm{O}_{2}\right)$ accumulation after staining berries with diaminobenzidine (DAB) according to Peng et al. (30), with some modifications. Before staining with $\mathrm{DAB}$, berries were immersed for $10 \mathrm{~s}$ in chitosan acetate and incubated for $24 \mathrm{~h}$ at $20 \pm 1{ }^{\circ} \mathrm{C}$ and 95 to $98 \% \mathrm{RH}$ (experiment 1 ). To evaluate whether $B$. cinerea inoculation of chitosan-treated berries would increase the production of $\mathrm{H}_{2} \mathrm{O}_{2}$ in table grape skins, berries were sprayed with a conidial suspension $\left(1.0 \times 10^{6}\right.$ conidia/ml) of $B$. cinerea $24 \mathrm{~h}$ after immersion in the different chitosan solutions, then incubated at $20 \pm 1{ }^{\circ} \mathrm{C}$ and 95 to $98 \% \mathrm{RH}$ for $48 \mathrm{~h}$ (experiment 2). Berries immersed in deionized water at pH 5.6 were used as a control. Each experiment was repeated twice. Ten berries were rinsed with deionized water, placed in a $400-\mathrm{ml}$ beaker containing $250 \mathrm{ml}$ of $1 \%$ (wt/vol) of DAB, and infused under vacuum at 0.25 atmospheres for $10 \mathrm{~min}$ to allow the penetration of the stain. Berries were kept at $20 \pm 1^{\circ} \mathrm{C}$ for $15 \mathrm{~h}$, transferred into $95 \%$ ( vol $/ \mathrm{vol}$ ) ethanol, boiled for $5 \mathrm{~min}$ until clear, and stored in fresh $95 \%$ (vol/vol) ethanol. DAB polymerizes instantly at the sites of peroxidase activity into a reddish-brown polymer (41). Berry skin samples $\approx 10 \mathrm{~mm}^{2}$ in size were placed on a slide and observed with a microscope (Leitz Dialux 22; Leitz, Wetzlar, Germany) under $\times 40$ magnification. Digital images were captured. The amount of stained area in the image was deter- mined by first thresholding each image by use of FoveaPro 3.0 filters (Reindeer Graphics Inc., Asherville, NC) installed in Adobe Photoshop. Briefly, the image was first duplicated and then the color of the stained area in the duplicate image was selected and adjusted. The duplicate was subtracted from the original, leaving the stained area against a gray background. The image was thresholded using the color-thresholding filter. The thresholded image was saved in a grayscale "tiff" format. The black and white areas of the thresholded image were later measured by use of the measurement macro of NIH Image.

Statistical analysis. Homogeneity of variances was tested using Levene's test. To normalize the data, appropriate transformations were determined empirically using normal probability plots. Arcsin of the square root of the proportion was applied to the decay incidence data. Values were submitted to analysis of variance and the means were separated by Fisher's protected least significant difference test (SuperANOVA; Abacus Concepts, Inc., Berkeley, CA). The decay incidence of chitosan dissolved in different acids to control the gray mold was ranked in each experiment according to Friedman's nonparametric test. For the data of oxygen and carbon dioxide contents in bags containing grape clusters, quadratic interaction models were fit to the averages, and predictions and $95 \%$ confidence intervals were calculated by these models (SAS Institute, Cary, NC). Correlations between the effectiveness of chitosan, viscosity and thickness of the coating, and induction in the berries of hydrogen peroxide were evaluated by bivariate analysis, and Pearson's correlation coefficient was calculated (SPSS Inc., Chicago).

\section{RESULTS}

Acids. Of the 15 acids tested, 10 were able to dissolve chitosan at $1 \%$ concentration (wt/vol or $\mathrm{vol} / \mathrm{vol}$ ) (Table 1 ); 3 of them (hydrochloric, L-ascorbic, and L-glutamic) required warming. Five acids were not able to dissolve the biopolymer, even after warming. The $\mathrm{pH}$ of $1 \%$ acid solutions that were able to dissolve chitosan was 0.6 (hydrochloric) to 2.8 (acetic), whereas that of acids that were not able to dissolve the biopolymer was 2.9 (gallic and trans-cinnamic) to 5.4 (DL- $\alpha$-aminobutyric).

Experiment with single detached berries. Chitosan, dissolved in any of the acids tested, was effective in reducing gray mold incidence on single table grape berries (Fig. 1) of cvs. Thompson Seedless and Autumn Seedless and the selection B36-55, all of which had been inoculated with $B$. cinerea before the immersion in the solutions. In preliminary trials carried out with grape cv. Italia, no significant difference in decay incidence was observed between berries treated with deionized water at $\mathrm{pH} 5.6$ and berries treated with $0.1 \%$ (wt/vol) of surfactant Triton X-100 at $\mathrm{pH}$ 5.6. In most of the trials, significant differences in effectiveness were observed among the chitosan solutions obtained by dissolving the biopolymer in the tested acids. The greatest reduction in gray mold decay, $\approx 70 \%$ compared with the control on Thompson Seedless and Autumn Seedless berries, was observed after immersion of the berries in chitosan dissolved in acetic or formic acids. The greatest gray mold reductions on B36-55 berries were 79, 78, and $70 \%$ after immersion in chitosan dissolved in acetic, hydrochloric, or formic acids, respectively. Overall, the lower decay reductions of 23 and 34\% were observed on grape treated with chitosan dissolved in malic or maleic acids, respectively (Fig. 1). On detached Autumn Seedless berries, disease severity was reduced by chitosan dissolved in any of acids tested. The greatest severity reduction, $63 \%$, was recorded after immersion of berries in chitosan dissolved in formic acid (data not shown). Similar results were obtained on Thompson Seedless and B36-55 (data not shown). Rank analysis indicated that the most effective treatments in reducing gray mold in all single-berry experiments incubated at $15 \pm 1{ }^{\circ} \mathrm{C}$ were immersion of berries in chitosan acetate or formate, whereas intermediate effectiveness was ob- 
served with chitosan dissolved in hydrochloric, lactic, L-glutamic, phosphorous, succinic, or L-ascorbic acids (data not shown). The least effective treatments were chitosan dissolved in maleic or malic acids.

Gray mold among single berries of cv. Italia inoculated with $B$. cinerea and immersed for $10 \mathrm{~s}$ in $1 \%$ solutions of each acid alone at $\mathrm{pH} 5.6$ was not significantly different from each other or the control, whereas berries immersed in chitosan solutions at the same $\mathrm{pH}$ showed a reduced disease incidence (Fig. 2). The highest decay reductions (58.6 and 55\%) compared with the control were observed in berries treated with chitosan acetate or formate acid, respectively.

On single berries of B36-55 selection immersed in the chitosan solutions before inoculation with $B$. cinerea, the greatest decay reductions compared with the control, 87 and $84 \%$, occurred after immersion in chitosan dissolved in acetic or hydrochloric acids, respectively, followed by a $74 \%$ reduction caused by chitosan formate (Fig. 3). Berries treated with chitosan dissolved in lactic and malic acids were sticky, whereas all other solutions did not cause any stickiness, abnormal smell, or change in appearance. On $<10 \%$ of the berries of the B36-55 selection and cv. Perlette (used in preliminary trials), chitosan dissolved in formic acid caused small blemishes.

Experiment with table grape clusters. In the trials carried out with small clusters, all chitosan solutions, with the exception of that prepared with maleic acid applied to Thompson Seedless grape, significantly reduced gray mold infections compared with the control (Fig. 4). In both Thompson Seedless and Crimson Seedless grape, chitosan dissolved in lactic acid resulted in the highest decay reductions, 60 and $62 \%$, respectively. Overall, malic and maleic acids were the least effective, as assessed by rank analysis (data not shown). The performance of chitosan solutions in trials conducted with single berries incubated at $15 \pm$ $1^{\circ} \mathrm{C}$ significantly correlated (Pearson correlation $=0.781, P=$ $0.005)$ with that of chitosan solutions in trials with cold stored grape clusters.

Cold storage gas exchange study. The analysis of air samples from stored grape berries showed an increased respiration rate during the first 5 weeks of storage at $0.5 \pm 1{ }^{\circ} \mathrm{C}$ (Fig. 5). The highest $\mathrm{CO}_{2}$ and the lowest $\mathrm{O}_{2}$ concentrations were measured within bags with control grape and grape berries treated with chitosan dissolved in formic acid. The lowest $\mathrm{CO}_{2}$ and the highest $\mathrm{O}_{2}$ concentrations were measured within bags with grape berries treated with chitosan dissolved in acetic or succinic acid. Regression equations can be used to predict carbon dioxide and oxygen content, respectively, across time for each acid used. The quadratic model is defined as $a+(b \times x)+\left(c \times x^{2}\right)$, where $a$ is the intercept, $b$ is the linear coefficient, $c$ is the quadratic term, and $x$ is time in weeks. For instance, the percentage of carbon dioxide in bags containing grape berries treated with acetic acid after 5 weeks of storage was $0.088+(-0.110 \times 5)+(0.032 \times 25)=$ 0.338 .

Viscosity of chitosan solutions. The measurements of the viscosity of chitosan solutions showed a 160 -fold difference between the least viscous acid (1.91 cp, L-ascorbic acid) and the most viscous acid (306.41 cp, maleic acid) (Table 2). Following L-ascorbic acid with increasing viscosity were chitosan solutions dissolved in hydrochloric, L-glutamic, acetic, malic, phosphorous, and formic acid. Viscosity was not correlated with effectiveness of chitosan solution in controlling gray mold decay.

Thickness of chitosan coatings. Chitosan film on the surface of Crimson Seedless berries immersed in chitosan solutions and microscopically studied is shown in Figure 6. The data of the two experiments were combined because the variances were homogeneous. The film appeared uniform in all the berries coated with chitosan dissolved in any acid except for the malic and maleic acids. The coating was the thickest $(13.1 \mu \mathrm{m})$ when dissolved in L-ascorbic acid which was approximately twice as thick as when

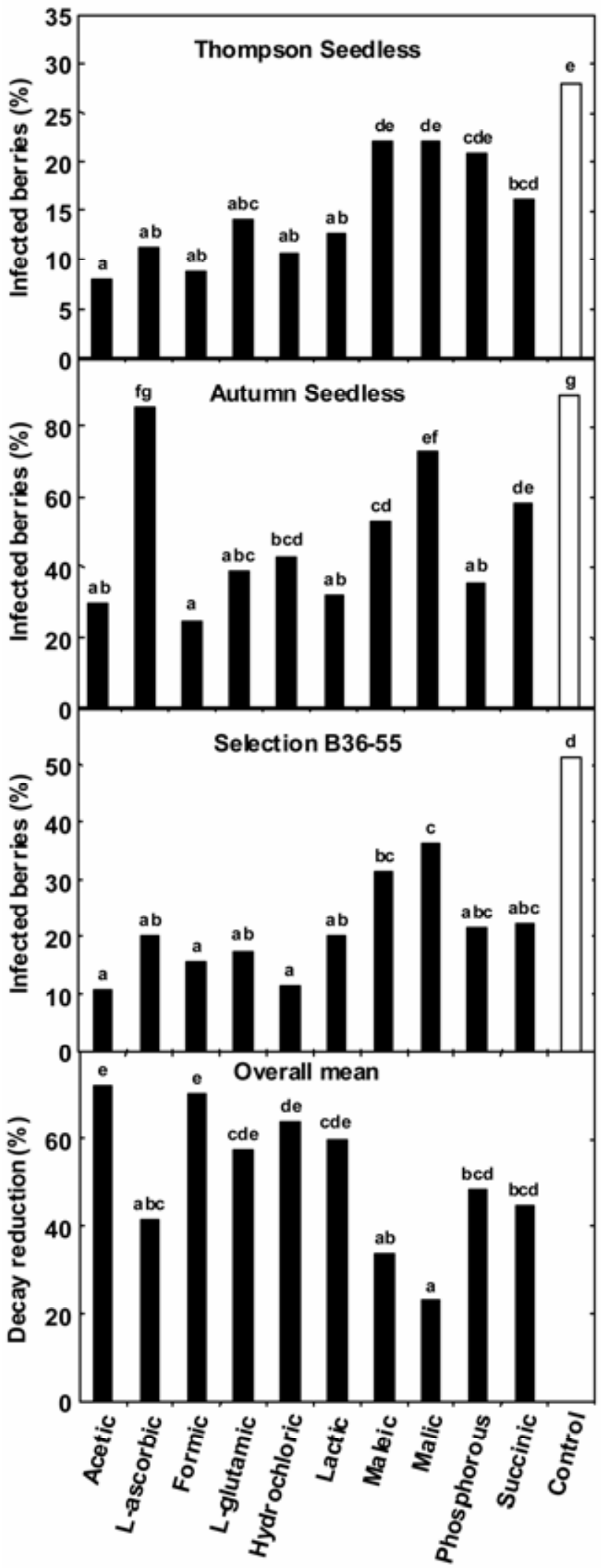

Fig. 1. Gray mold incidence of single berries of cvs. Thompson Seedless, Autumn Seedless, and selection B36-55 treated with chitosan dissolved in various acids. Berries were inoculated by spraying with Botrytis cinerea at 1.0 $\times 10^{5}$ conidia/ml, air dried for $30 \mathrm{~min}$, and immersed for $10 \mathrm{~s}$ in $1 \%$ chitosanacid solutions. Berries immersed in deionized water at $\mathrm{pH} 5.6$ were used as controls. After air drying, berries were stored at $15 \pm 1{ }^{\circ} \mathrm{C}$ and 95 to $98 \%$ relative humidity for 7 days. In the bottom panel, the mean decay reduction was calculated from all three trials. Values on columns topped with the same letter are not statistically different according to Fisher's protected least significant difference $(P \leq 0.01)$. 
dissolved in acetic acid $(6.5 \mu \mathrm{m})$ (Table 2). The thickness of the chitosan coatings did not correlate with viscosity, efficacy of the treatments to control gray mold, or $\mathrm{CO}_{2}$ and $\mathrm{O}_{2}$ exchange rates.

Detection of ROS. ROS in berry skin was induced in $10.03 \pm$ $3.07 \%$ of the stained area by inoculation with $B$. cinerea whereas only $4.64 \pm 2.12 \%$ of the area of control berries was stained. No ROS induction was observed in grape berries treated with chitosan acetate $(3.29 \pm 1.67 \%$ of the area stained). The skin of grape berries immersed in chitosan dissolved in L-ascorbic or phosphorous acid and later inoculated with $B$. cinerea showed an increase of ROS compared with that of the control (grape berries inoculated with $B$. cinerea only) (data not shown). ROS production was not correlated with any of the other recorded parameters;

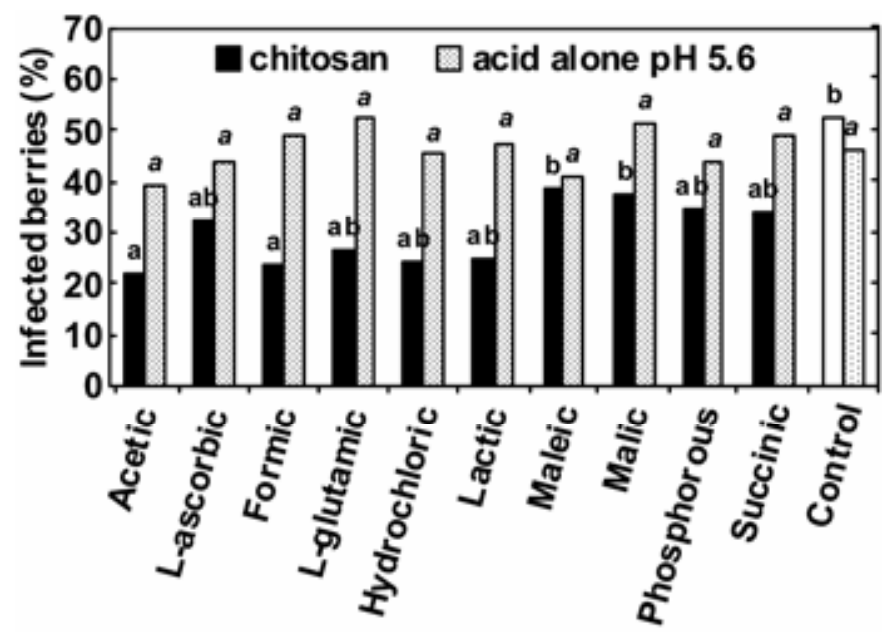

Fig. 2. Gray mold incidence of single berries of cv. Italia treated with chitosan dissolved in the different acids and with the acids alone at $\mathrm{pH}$ 5.6. Berries were inoculated by spraying with Botrytis cinerea at $1.0 \times 10^{5}$ conidia/ml, air dried for $30 \mathrm{~min}$, and immersed for $10 \mathrm{~s}$ in $1 \%$ chitosan-acid solutions or in a $1 \%$ solution of each acid alone. Berries immersed in deionized water at $\mathrm{pH} 5.6$ were used as controls. After air drying, berries were stored at $15 \pm 1{ }^{\circ} \mathrm{C}$ and 95 to $98 \%$ relative humidity for 7 days. Values on columns topped the same letter are not statistically different according to Fisher's protected least significant difference $(P \leq 0.01)$.

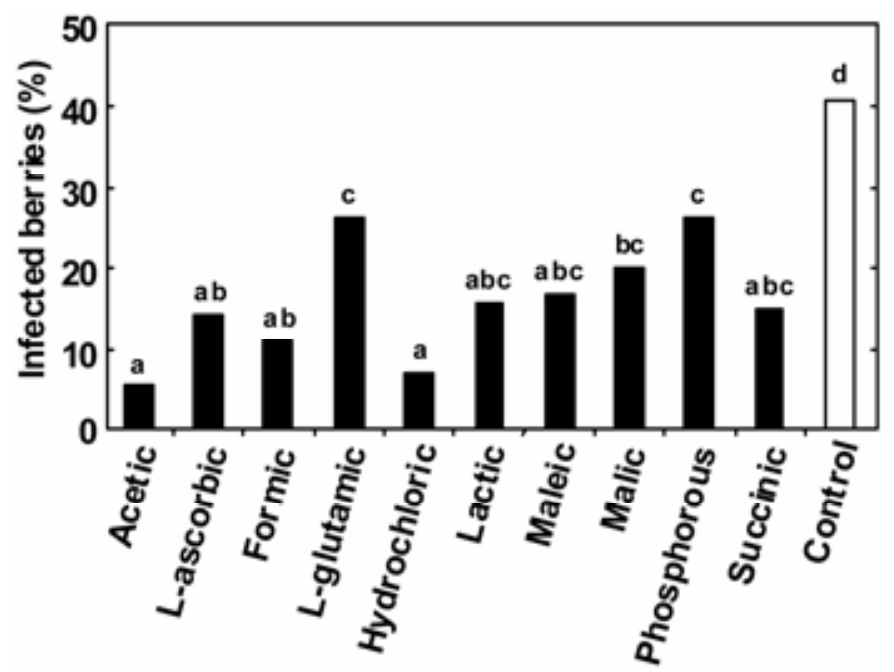

Fig. 3. Gray mold incidence of single grape berries of selection B36-55 treated with chitosan. Berries were first immersed for $10 \mathrm{~s}$ in $1 \%$ chitosanacid solutions, air dried for $30 \mathrm{~min}$, and inoculated by spraying with Botrytis cinerea at $1.0 \times 10^{5}$ conidia/ml. Berries immersed in deionized water at $\mathrm{pH}$ 5.6 were used as controls. After air drying, berries were stored at $15 \pm 1^{\circ} \mathrm{C}$ and 95 to $98 \%$ relative humidity for 7 days. Values of columns topped with the same letter are not statistically different according to Fisher's protected least significant difference $(P \leq 0.01)$. namely, disease incidence, disease severity, viscosity, coating thickness, and oxygen and carbon dioxide contents (data not shown).

\section{DISCUSSION}

Chitosan is a natural biopolymer that must be dissolved in a slightly acidic solution in order to activate its antimicrobial activity and eliciting properties (7). Chitosan dissolved in acetic acid is not different in effectiveness from water-soluble glycol chitosan to control postharvest gray mold of table grape and is a cheaper alternative (G. Romanazzi, unpublished data). Of the 15 acids we tested, 10 were able to dissolve chitosan at $1 \%$ concentration; 4 of those (L-ascorbic, maleic, phosphorous, and succinic) were not previously reported to be able to dissolve the biopolymer. The ability of acids to dissolve chitosan was greatly dependent on their $\mathrm{pH}$; those that successfully dissolved it had a $\mathrm{pH}$ at this concentration of 0.6 to 2.8 , while the acids that were not able to dissolve the biopolymer had a $\mathrm{pH}>2.9$. In our trials, we dissolved the biopolymer in both inorganic (hydrochloric and phosphorous) and organic (acetic, L-ascorbic, formic, L-glutamic, lactic, maleic, malic, and succinic) acids. Several organic acids have been shown to control postharvest decay of fruit. Acetic, peracetic, formic, sorbic, and propionic acids reduced decay of table grape, sweet cherry, apple, pear, and citrus $(22,29,39,40)$. The effectiveness of the acids alone was tested at the same concentration and $\mathrm{pH}$ as the chitosan solutions, and they were unable to reduce gray mold decay and, thus, contribute to the activity of chitosan solutions. These findings corroborate the work of similar

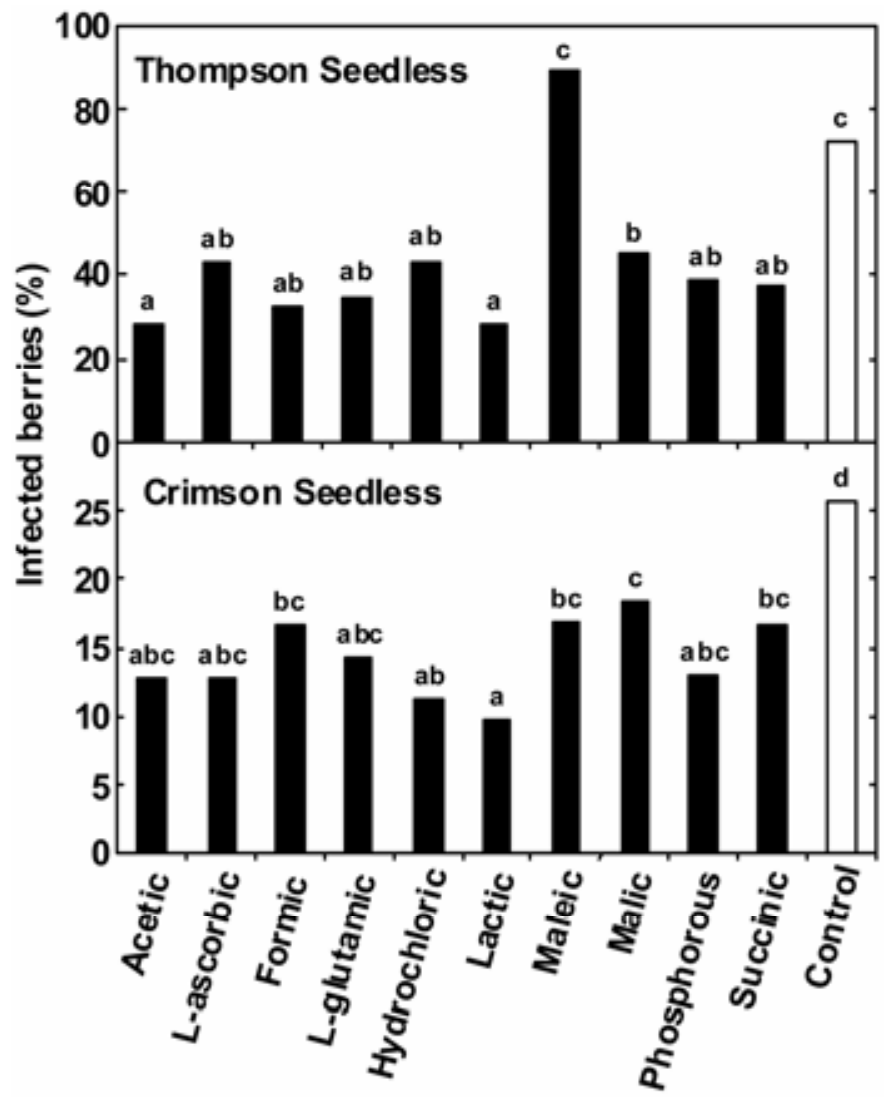

Fig. 4. Gray mold incidence of cvs. Thompson Seedless and Crimson Seedless grape clusters immersed for $10 \mathrm{~s}$ in $1 \%$ chitosan-acid solution. Clusters were inoculated before treatment by spraying with Botrytis cinerea at $1.0 \times 10^{5}$ conidia/ml and air dried for $30 \mathrm{~min}$ after inoculation. Clusters immersed in deionized water at $\mathrm{pH} 5.6$ were used as controls. After air drying, clusters were stored at $0.5 \pm 1{ }^{\circ} \mathrm{C}$ and 95 to $98 \%$ relative humidity for 60 days. Values of columns topped with the same letter are not statistically different according to Fisher's protected least significant difference $(P \leq 0.01)$. 
studies conducted on strawberry (15) and apple (13). Chung et al. (10) found that the in vitro activity of $0.25 \%$ hydrochloric, formic, or acetic acids at $\mathrm{pH} 5$ and 6 on Escherichia coli was negligible compared with that of chitosan dissolved in the same acids at the same $\mathrm{pH}$.

The grape berries coated with chitosan dissolved in lactic and malic acids were sticky. This property would limit the possible use of these solutions for coating fruit. A stickiness of the film obtained by dissolving chitosan in lactic and malic acids was also observed by Nadarajah et al. (26).

The chitosan solutions used in our experiments, with the exception of formate, were not phytotoxic in any of the trials. No phytotoxicity of treatments with chitosan acetate and chloride was reported on strawberry, Japanese pear, kiwifruit, or table grape $(9,12,15,37)$. Formic acid used alone caused some injuries to citrus and stone fruit but not to pome fruit (39). In our trials, we observed a slight phytotoxicity after immersion of grape berries of the cv. Perlette and those of the B35-55 selection in chitosan dissolved in formic acid.

Few reports are available that compare the antimicrobial activity of chitosan dissolved in different acids. Our results suggests that organic acids with low carbon number, such as formic, acetic, and lactic acids, are better solvents for chitosan and performed better in controlling gray mold on grape than those with higher carbon numbers (maleic, malic, succinic, L-ascorbic, and Lglutamic acids) or inorganic acids such as hydrochloric or phosphorous acids. Chung et al. (10) reported similar findings using chitosan to control waterborne pathogens such as E. coli and Staphylococcus aureus.

All chitosan solutions, except those prepared with malic or maleic acids, significantly reduced the incidence of blue mold, caused by natural occurring Penicillium spp. inoculum, confirm- ing prior results obtained with chitosan acetate (35). Chitosan solutions were effective in reducing gray mold of grape on both single detached berries after 7 days at $15 \pm 1^{\circ} \mathrm{C}$ and small clusters stored at $0.5 \pm 1{ }^{\circ} \mathrm{C}$ for 60 days. The performance of chitosan solutions in the trials conducted with different grape portions stored in two diverse conditions correlated with each other. The possibility to effectively use a chitosan treatment to control gray mold of grape in several environments is supported by its efficacy as a preharvest application to control postharvest decay of strawberry, table grape (other studies), and sweet cherry $(31,36,37)$. Chitosan can work effectively in different conditions of storage temperature and time of application whereas other alternatives to conventional fungicide sprays, such as biological control using

TABLE 2. Viscosity of chitosan ( \pm standard deviation [SD]) dissolved in different acids and thickness of chitosan coating $( \pm \mathrm{SD})$ measured on table grape berries

\begin{tabular}{lcrcc}
\hline Acid & ${\text { Viscosity }(\mathrm{cp})^{\mathrm{a}}}$ & SD & ${\text { Coating }(\mu \mathrm{m})^{\mathrm{b}}}$ & SD \\
\hline Acetic & 43.5 & 4.5 & 6.5 & 1.9 \\
L-ascorbic & 1.9 & 0.2 & 13.1 & 2.8 \\
Formic & 234.9 & 21.2 & 9.8 & 1.8 \\
L-glutamic & 23.8 & 2.7 & 9.8 & 1.9 \\
Hydrochloric & 3.9 & 0.6 & 11.2 & 2.3 \\
Lactic & 102.9 & 11.1 & 9.7 & 1.9 \\
Maleic & 306.4 & 8.6 & 9.1 & 3.2 \\
Malic & 148.4 & 10.1 & 10.7 & 1.2 \\
Phosphorous & 178.1 & 13.1 & 9.6 & 1.1 \\
Succinic & 12.9 & 2.0 & 7.4 & 2.6 \\
\hline
\end{tabular}

${ }^{a}$ Viscosity of chitosan solutions, in centipoises (cp), was assessed with a viscometer according to the falling ball method (21).

b Thickness of chitosan coating was measured with a confocal laser scanning microscope.

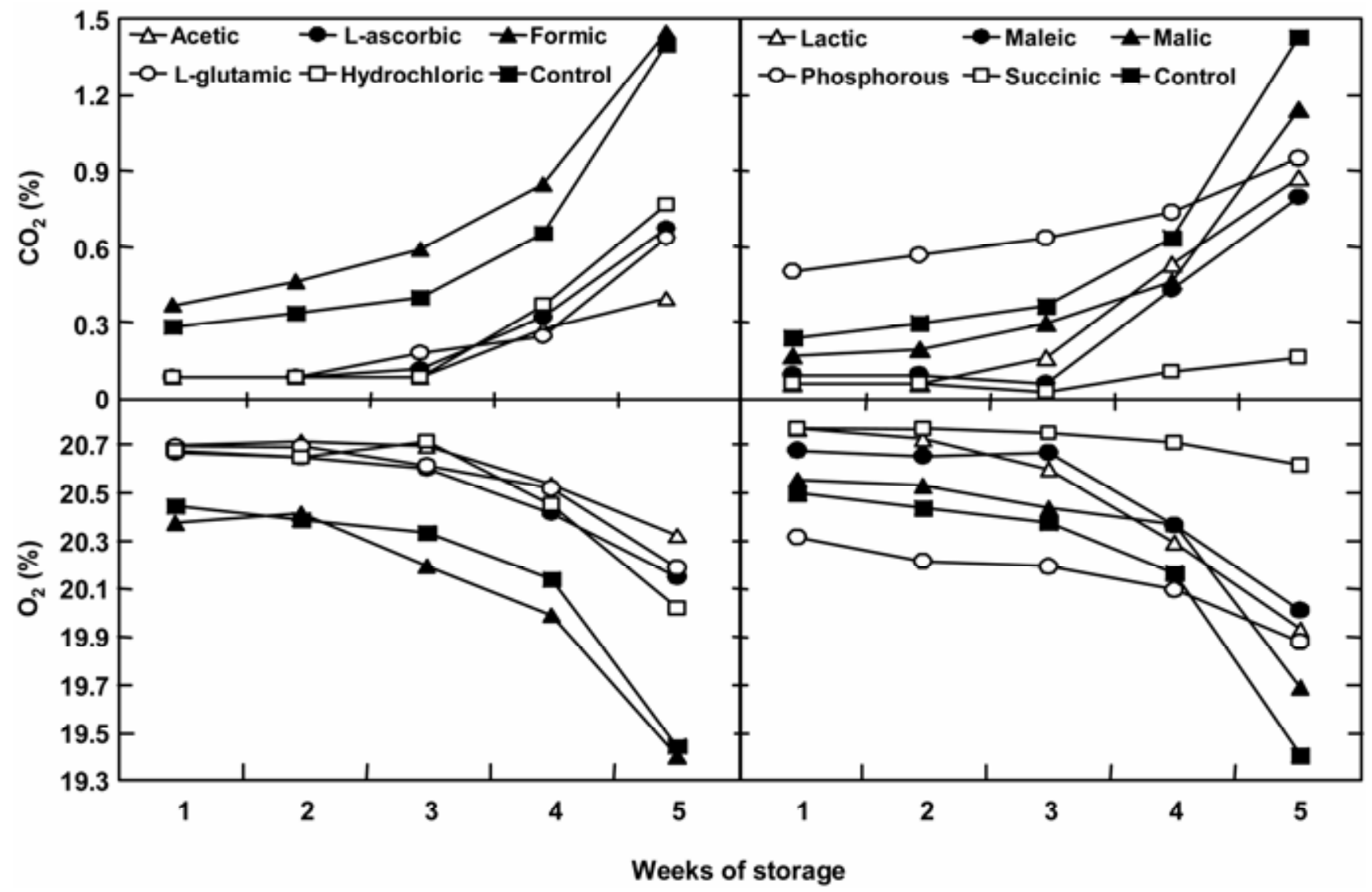

Fig. 5. Oxygen and carbon dioxide concentrations inside 0.5-liter-volume plastic bags where Crimson Seedless grape clusters were enclosed after immersion in chitosan-acid solution stored at $0.5 \pm 1^{\circ} \mathrm{C}$ for 5 weeks. The 10 chitosan solutions were divided into two panels to avoid overlapping of lines, with control treatments (immersion in deionized water) in both panels. 

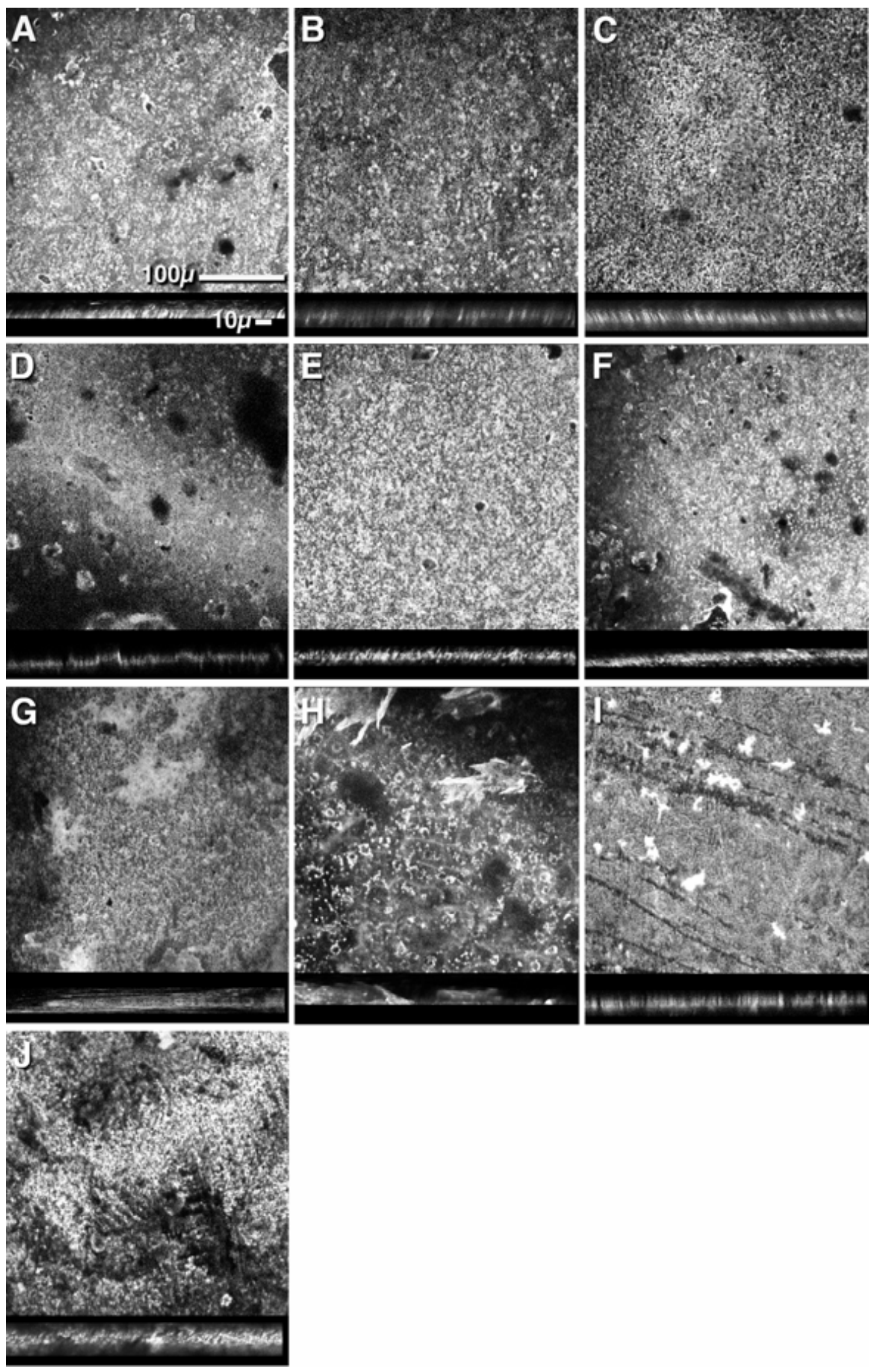

Fig. 6. Appearance of chitosan coating after immersing Crimson Seedless grape berries in $1 \%$ chitosan dissolved in different acids. A, Acetic acid; B, L-ascorbic acid; C, formic acid; D, L-glutamic acid; E, hydrochloric acid; F, lactic acid; G, maleic acid; H, malic acid; I, phosphorous acid; and J, succinic acid. For each chitosan solution, the upper panel displays the surface appearance and the lower panel the cross section of the coating. 
applications with antagonistic microorganisms (17), could require a narrower range of environmental conditions to be fully effective.

Rank analysis showed that chitosan acetate or formate were the most effective to control decay on grape berries at $15 \pm 1{ }^{\circ} \mathrm{C}$ whereas, on those stored at $0.5 \pm 1{ }^{\circ} \mathrm{C}$, the best performance was observed with chitosan lactate or acetate. It is likely that storage temperature could have influenced the interaction between the biopolymer, the acid, the host tissues, and the pathogen that altered the effectiveness of the chitosan solutions to control gray mold.

The control of gray mold decay when the chitosan treatments were applied before the inoculation with $B$. cinerea (i.e., conidia of the pathogen were deposited on the chitosan film) was similar to that obtained by treating berries after inoculation with the pathogen. This implies that the activity of chitosan film is based on its antifungal and eliciting properties rather than acting as a simple mechanical barrier (2). It has been reported that chitosan does not kill the conidia of $B$. cinerea but, rather, inhibits conidial germination and causes abnormal growth of the pathogen (14).

The thickness of chitosan films on grape berries was not correlated with their effectiveness to control gray mold. In fact, the thickest film produced by chitosan dissolved in L-ascorbic acid was intermediate in effectiveness to control gray mold, while the most effective was chitosan acetate, which created the thinnest film. The uneven and lumpy coating created by chitosan dissolved in malic or maleic acid may explain partially the low efficacy of these treatments in reducing gray mold decay. On the other hand, chitosan dissolved in acetic and formic acids formed a smooth coating, as was also observed by Nadarajah et al. (26). The viscosity of chitosan solutions varied greatly, and this property should be considered for its influence on the application of chitosan. Among the most effective chitosan solutions, chitosan acetate had the lowest viscosity compared with lactate or formate. Obviously, low viscosity is preferred when applications are done by spraying.

$\mathrm{CO}_{2}$ and $\mathrm{O}_{2}$ exchange of chitosan-treated grape berries, with the exception of the biopolymer dissolved in formic acid, was lower than that of control grape berries. A tendency to a reduction of $\mathrm{CO}_{2}$ and $\mathrm{O}_{2}$ exchange was reported on grape berries treated with $0.5 \%$ chitosan alone or combined with 10 or $20 \%$ ethanol (34) Because, in our trials, we used $1 \%$ chitosan concentration, its effect to decrease $\mathrm{CO}_{2}$ and $\mathrm{O}_{2}$ exchange was amplified. These phenomena can be ascribed to a reduced respiration in chitosancoated berries, as previously reported for strawberry, raspberry, and peach $(15,18,45)$. In our experiments, chitosan formate caused some phytotoxicity on grape berries of cv. Perlette and those of the selection B36-55. The increased respiration observed in grape berries treated with chitosan formate can be ascribed to the damage on host tissues. The greatest reduction in respiration of stored grape berries was caused by chitosan dissolved in acetic and succinic acid, although succinic acid solution was not as effective as acetic to control gray mold decay. The developed model can be useful to follow the $\mathrm{O}_{2}$ and $\mathrm{CO}_{2}$ progress and could predict the respiration over time of chitosan-coated table grape berries.

Chitosan acetate was also the most effective control of gray mold, which agrees with findings of Lougheed et al. (20), Wilson et al. (42), and Baldwin et al. (5), who reported a positive correlation between reduced respiration, delayed senescence, and reduced susceptibility to decay. In trials with strawberry and peach, a reduced respiration rate was caused by treatment with chitosan acetate and was correlated with improved quality attributes of the fruit $(15,18)$.

In our trials, an ROS-positive reaction was not induced by chitosan treatment whereas it was stimulated by $B$. cinerea inoculation. Induction of hydrogen peroxide by chitosan is reported in grapevine cell suspensions, although more hydrogen peroxide production is detected when $B$. cinerea cell-wall elicitors are added to the suspension (32). It is possible that the relatively thick cuticle of berries of the selection B36-55, measured by Mlikota Gabler et al. (25), prevented contact of chitosan with the epidermal cells while its eliciting activity was unimpeded in the cell suspension. El Ghaouth et al. (14) reported that chitosan induced chitinase activity in wounded strawberry fruit but not in intact fruit, and suggested that the nonporous strawberry cuticle might have physically separated chitosan from the tissue and, therefore, prevented chitosan from inducing chitinase. A similar explanation may be true for the poor ROS-positive reaction observed in this study.

Chitosan does not affect the naturally occurring microflora of grape (37), which is profoundly affected by treatments with sulfur dioxide $(27,37)$. Chitosan treatment can be particularly suitable for certified organic growers where sulfur dioxide cannot be used as a postharvest treatment of table grape (24). In our tests with table grape, we didn't evaluate the chitosan impact on taste. However, sensorial analyses carried out by $\mathrm{Xu}$ et al. (44) showed a beneficial effect of chitosan treatment in terms of delaying rachis browning and dehydration and maintenance of visual aspect of the berry without detrimental effects on taste or flavor.

Chitosan dissolved in any of the acids tested reduced postharvest gray mold of table grape. The decay reduction depended on the acid chitosan was dissolved in. The greatest reduction of gray mold decay of table grape berries and clusters was observed after immersion in chitosan dissolved in any acetic, formic, or lactic acids; the least decay reduction was when chitosan was dissolved in either maleic or malic acids. Physical properties such as viscosity and coating thickness on berries were greatly dependent on the chitosan-acid solution pair. Chitosan dissolved in acetic acid reduced decay effectively, did not cause any phytotoxicity, reduced $\mathrm{CO}_{2}$ and $\mathrm{O}_{2}$ exchange of the grape berries, and was the best acid for dissolving chitosan. As a nontoxic biodegradable material and as an elicitor, chitosan has the potential to become a new class of plant protectant (6), although further investigations are necessary to better understand the mechanisms of action related to its effectiveness in the control of gray mold.

\section{ACKNOWLEDGMENTS}

Most of the experiments were conducted at the USDA-ARS, San Joaquin Valley Agricultural Sciences Center, Parlier, CA, while trials on grape cv. Italia were carried out at Marche Polytechnic University, Ancona, Italy. A portion of this work was funded by an Italian National Research Council (CNR) fellowship program (Bando n. 203.22). We thank M. Santini for collaboration in the trials carried out on table grape cv. Italia and D. Obenland and S. Roller for reviewing this manuscript.

\section{LITERATURE CITED}

1. Allan, C. R., and Hadwiger, L. A. 1979. The fungicidal effect of chitosan on fungi of varying cell wall composition. Exp. Mycol. 3:285-287.

2. Amborabé, B.-E., Bonmort, J., Fleurat-Lessard, P., and Roblin, G. 2008. Early events induced by chitosan on plant cells. J. Exp. Bot. 59:23172324.

3. Anonymous. 1986. GRAS status of sulfating agents for use on fresh and frozen foods revoked. Fed. Regist. 51:25021.

4. Aziz, A., Trotel-Aziz, P., Dhuicq, L., Jeandet, P., Couderchet, M., and Vernet, G. 2006. Chitosan oligomers and copper sulfate induce grapevine defense reactions and resistance to gray mold and downy mildew. Phytopathology 96:1188-1194.

5. Baldwin, E. A., Nisperos-Carriedo, M. O., and Baker, R. A. 1995. Use of edible coatings to preserve quality of lightly (and slightly) processed products. Crit. Rev. Food Sci. Nutr. 35:509-524.

6. Bautista-Baños, S., Hernández-Lauzardo, A. N., Velázquez-del Valle, M. G., Hernández-López, M., Ait Barka, E., Bosquez-Molina, E., and Wilson, C. L. 2006. Chitosan as a potential natural compound to control pre and postharvest diseases of horticultural commodities. Crop Prot. 25:108-118.

7. Bégin A., and Van Calsteren, M. R. 1999. Antimicrobial films produced by chitosan. Int. J. Biol. Macromol. 26:63-67. 
8. Benhamou, N., Lafontaine, P. J., and Nicole, M. 1994. Induction of systemic resistance to Fusarium crown root rot in tomato plants by seed treatment with chitosan. Phytopathology 84:1432-1444.

9. Camili, E. C., Benato, E. A., Pascholati, S. F., and Cia, P. 2007. Evaluation of chitosan on postharvest protection of 'Itália' grapes against Botrytis cinerea. Summa Phytopathol. 33(3):215-221.

10. Chung, Y. C., Wang, H. L., Chen, Y. M., and Li, S. L. 2003. Effect of abiotic factors on the antibacterial activity of chitosan against waterborne pathogens. Bioresour. Technol. 88:179-184.

11. Droby, S., and Lichter, A. 2004. Post-harvest Botrytis infection: etiology, development and management. Pages 349-367 in: Botrytis: Biology, Pathology and Control. Y. Elad, B. Williamson, P. Tudzynski, and N. Delen, eds. Kluwer Academic Publishers, London.

12. Du, J., Gemma, H., and Iwahori, S. 1997. Effects of chitosan coating on the storage of peach, Japanese pear and kiwifruit. J. Jpn. Soc. Hortic. Sci. $66: 15-22$.

13. Du, J., Gemma, H., and Iwahori, S. 1998. Effects of chitosan coating on the storability and on the ultrastructural changes of 'Jonagold' apple fruit in storage. Food Preserv. Sci. 24:23-29.

14. El Ghaouth, A., Arul, J., Grenier, J., and Asselin, A. 1992. Antifungal activity of chitosan on two postharvest pathogens of strawberry fruits. Phytopathology 82:398-402.

15. El Ghaouth, A., Arul, J., Ponnampalam, R., and Boulet, M. 1991. Chitosan coating effect on storability and quality of fresh strawberries. J. Food Sci. 56:1618-1620.

16. Elmer, P. A. G., and Reglinski, T. 2006. Biosuppression of Botrytis cinerea in grapes. Plant Pathol. 55:155-177.

17. Janisiewicz, W. J., and Korsten, L. 2002. Biological control of postharvest diseases of fruits. Annu. Rev. Phytopathol. 40:411-441.

18. Li, H., and Yu, T. 2001. Effect of chitosan on incidence of brown rot, quality and physiological attributes of postharvest peach fruit. J. Sci. Food Agric. 81:269-274.

19. Lichter, A., Mlikota Gabler, F., and Smilanick, J. L. 2006. Control of spoilage in table grapes. Stewart Postharvest Rev. 6:1.

20. Lougheed, E. C., Murr, D. P., and Berard, L. 1978. Low pressure storage for horticultural crops. Hortscience 13:21-27.

21. MacLean-Fletcher, S. D., and Pollard, T. D. 1980. Viscometric analysis of the gelation of Acanthamoeba extracts and purification of two gelation factors. J. Cell Biol. 85:414-428.

22. Mari, M., Gregori, R., and Donati, I. 2004. Postharvest control of Monilinia laxa and Rhizopus stolonifer in stone fruit by peracetic acid. Postharvest Biol. Technol. 33:319-325.

23. Meng, X., Li, B., Liu, J., and Tian, S. 2008. Physiological responses and quality attributes of table grape fruit to chitosan preharvest spray and postharvest coating during storage. Food Chem. 106:501-508.

24. Mlikota Gabler, F., and Smilanick, J. L. 2001. Postharvest control of table grape gray mold on detached berries with carbonate and bicarbonate salts and disinfectants. Am. J. Enol. Vitic. 52:12-20.

25. Mlikota Gabler, F., Smilanick, J. L., Mansour, M., Ramming, D. W., and Mackey, B. E. 2003. Correlations of morphological, anatomical, and chemical features of grape berries with resistance to Botrytis cinerea. Phytopathology 93:1263-1273.

26. Nadarajah, K., Prinyawiwatkul, W., No, H. K., and Sathivel, S. 2006. Sorption behavior of crawfish chitosan films as affected by chitosan extraction processes and film casting solvents. J. Food Sci. 71:E33E39.

27. Nelson, K. E., and Richardson, H. B. 1967. Storage temperature and sulfur dioxide treatment in relation to decay and bleaching of stored grapes. Phytopathology 57:950-955.
28. Noctor, G., and Foyer, C. H. 1998. Ascorbate and glutathione: keeping active oxygen under control. Annu. Rev. Plant Physiol. Plant Mol. Biol. 49:249-279.

29. Palou, L., Usall, J., Smilanick, J. L., Aguilar, M.-J., and Vinas, I. 2002. Evaluation of food additives and alternative chemicals for the control of Penicillium digitatum Sacc. and Penicillium italicum Wehmer on citrus fruit. Pest Manage. Sci. 58:459-466.

30. Peng, J.-L., Bao, Z.-L., Ren, H.-Y., Wang, J.-S., and Dong, H.-S. 2004 Expression of harpin ${ }_{\mathrm{Xoo}}$ in transgenic tobacco induces pathogen defense in the absence of hypersensitive cell death. Phytopathology 94:10481055.

31. Reddy, B. M. V., Belkacemi, K., Corcuff, R., Castaigne, F., and Arul, J. 2000. Effect of pre-harvest chitosan sprays on post-harvest infection by Botrytis cinerea and quality of strawberry fruit. Postharvest Biol. Technol. 20:39-51.

32. Repka, V. 2001. Elicitor stimulated induction of defense mechanisms and defense gene activation in grapevine cell suspension culture. Biol. Plant. 44:555-565.

33. Roller, S., and Covill, N. 1999. The antifungal properties of chitosan in laboratory media and apple juice. Int. J. Food Microbiol. 47:67-77.

34. Romanazzi, G., Karabulut, O. A., and Smilanick, J. L. 2007a. Combination of chitosan and ethanol to control gray mold of table grapes. Postharvest Biol. Technol. 45:134-140.

35. Romanazzi, G., Mlikota Gabler, F., and Smilanick, J. L. 2006. Preharvest chitosan and postharvest UV-C irradiation treatments suppress gray mold of table grapes. Plant Dis. 90:445-450.

36. Romanazzi, G., Nigro, F., and Ippolito, A. 2003. Short hypobaric treatments potentiate the effect of chitosan in reducing storage decay of sweet cherries. Postharvest Biol. Technol. 29:73-80.

37. Romanazzi, G., Nigro, F., Ippolito, A., Di Venere, D., and Salerno, M. 2002. Effects of pre and postharvest chitosan treatments to control storage grey mold of table grapes. J. Food Sci. 67:1862-1867.

38. Romanazzi, G., Santini, M., Murolo, S., and Landi, L. $2007 \mathrm{~b}$. Antimicrobial and eliciting activity of chitosan in the control of gray mold of strawberries in storage. Pages 403-408 in Proc. COST 924 Novel Approaches for the Control of Postharvest Diseases and Disorders, Bologna, Italy.

39. Sholberg, P. L. 1998. Fumigation of fruit with short-chain organic acids to reduce the potential of postharvest decay. Plant Dis. 82:689-693.

40. Sholberg, P. L., Reynolds, A. G., and Gaunce, A. P. 1996. Fumigation of table grapes with acetic acid to prevent postharvest decay. Plant Dis. 80:1425-1428

41. Thordal-Christensen, H., Zhang, Z., Wei, Y., and Collinge, D. B. 1997. Subcellular localization of $\mathrm{H}_{2} \mathrm{O}_{2}$ in plants. $\mathrm{H}_{2} \mathrm{O}_{2}$ accumulation in papillae and hypersensitive response during the barley-powdery mildew interaction. Plant J. 11:1187-1194.

42. Wilson, C. L., El Ghaouth, A., Chalutz, E., Droby, S., Stevens, C., Lu, J. Y., Khan, V., and Arul, J. 1994. Potential of induced resistance to control postharvest diseases of fruits and vegetables. Plant Dis. 78:837-844.

43. Wu, T., Zivanovic, S., Draughon, F. A., Conway, W. S., and Sams, C. E. 2005. Physicochemical properties and bioactivity of fungal chitin and chitosan. J. Agric. Food Chem. 53:3888-3894

44. Xu, W. T., Huang, K. L., Guo, F., Qu, W., Yang, J. J., Liang, Z. H., and Luo, Y. B. 2007. Postharvest grapefruit seed extract and chitosan treatment of table grapes to control Botrytis cinerea. Postharvest Biol. Technol. 46:86-94.

45. Zhang, D., and Quantick, P. C. 1998. Antifungal effects of chitosan coating on fresh strawberries and raspberries during storage. J. Hortic. Sci. Biotechnol. 73:763-767. 